\title{
ANALISIS STRATEGI BISNIS PADA USAHA KEMPLANG PANGGANG FAJAR BANDAR LAMPUNG
}

\author{
Appin Purisky Redaputri ${ }^{1}$, Dandy Suganda ${ }^{2}$ \\ Faculty of Economic and Business, Universitas Bandar Lampung \\ J1. Z.A Pagar Alam No. 26 Labuhan Ratu, Kedaton, 35142, Bandar Lampung Indonesia \\ Email : \\ Dandy.17011217@student.ubl.ac.id \\ appin@ubl.ac.id
}

\begin{abstract}
ABSTRAK
Kemplang adalah sebuah kerupuk ikan yang umum ditemukan di belahan selatan Sumatra, Indonesia. Kerupuk kemplang umumnya terbuat dari ikantenggiri, yang dicampur dengan tepungtapioka dan penyedap rasa lain, dikeringkan dan kemudian dipanggang atau digoreng. Bentuk kemplang serupa dengan senbei dari negara Jepang. Salah satu usaha kemplang yang ada di Bandar Lampung adalah Kemplang Panggang Fajar. Awal mulanya usaha ini di bentuk karena untuk mengisi kekosongan waktu owner dari kemplang tersebut. Dikarenakan orang tua dari owner tersebut membuka usaha kemplang di daerah Prabumulih, Sumatera Selatan. Kemudian owner dari kemplang tersebut ingin belajar cara membuat kemplang mulai dari pembelian bahan, peralatan yang diperlukan, hingga proses pembuatannya. Kemudian seiring berjalannya waktu usaha tersebut mulai tumbuh menjadi usaha tetap. 3 bulan pertama usaha tersebut mengalami peningkatan penjualan, namun di 1 bulan terakhir minat konsumen menurun dan sehingga penjualan produk mengalami penurunan.

Alat analisis yang digunakan untuk menganalisis permasalahan yaitu analisisSWOT. Berdasarkan hasil pembahasan diagram Matrix SWOT diatas, diketahui Kemplang Panggang Fajar Bandar Lampung berada dikaudran I ,dimanasituasiyangsangatmenguntungkan. Padakuadran ini, Kemplang Panggang Fajar Bandar Lampung memiliki peluang dan kekuatan sehingga dapat memanfaatkan peluang yang ada. Strategiyangharusditerapkan dalam kondisi ini adalah mendukungkebijakan pertumbuhan penjualan.
\end{abstract}

Kata kunci : Strategi bisnis, penjualan, analisis SWOT. 


\section{Latar Belakang Masalah}

Bisnis kuliner merupakan salahsatu bidang usaha yang sedang banyak dijumpai di era millenial. Bisnis di bidang kuliner sendiri disebut-sebut sebagai bisnis yang sangat menguntungkan. Bisnis ini sendiri bisa dimulai dari usaha kecil dan masih bersifat usaha rumahan hingga usaha yang besar bahkan sampai bisa menjual franchise. Kemplangadalahsebuah kerupuk ikan yang umum ditemukan di belahan selatan Sumatra, Indonesia. $\quad$ Kerupuk kemplang umumnya terbuat dari ikan tenggiri, yang di campur dengan tepungtapioka dan penyedap rasa lain, dikeringkan dan kemudian dipanggang atau digoreng.

Bentukkemplangmiripdengan senbeidari Jepang. Salah satu usaha kemplang yang ada di Bandar Lampung adalah KemplangPanggangFajar. Awal mulanya usaha ini di bentuk karena untuk mengisi kekosongan waktu owner dari kemplang tersebut. Dikarenakan orang tua dari owner tersebut membuka usaha kemplang di daerah Prabumulih, Sumatera Selatan. Kemudian owner dari kemplang tersebut ingin belajar cara membuat kemplang mulai dari pembelian bahan, peralatan yang diperlukan, hingga proses pembuatannya. Kemudian seiring berjalannya waktu usaha tersebut mulai tumbuh menjadi usaha tetap. 3 bulan pertama usaha tersebut mengalami peningkatan penjualan, namun di 1 bulan terakhir minat konsumen menurun dan sehingga penjualan produk mengalami penurunan. Oleh karena itu owner mencari strategi terbaru untuk meningkatkan penjualannya kembali agar pendapatan bisa stabil atau bahkan bisa kembali naik seperti pada awal pembukaan usaha tersebut.

Keunggulan dari Kemplang Panggang Fajar adalah untuk sambalnya tidak menggunakan bahan pengawet yang dimana sambalnya pastinya memiliki rasa yang original dan tentunya enak.

penelitian : "Analisis Strategi Bisnis PADA USAHA KEMPLANG PANGGANG FAJAR BANDAR LAMPUNG"

\section{Identifikasi Masalah}

Berdasarkan latar belakang masalah diatas yang ada pada Mamikeki adalah sebagai berikut :

1. Berdasarkan tabel 1.1 terjadi penurunan pendapatan Mamikeki di Bandar Lampung dari bulan September 2020 - oktober 2020. 


\section{Tujuan Penelitian}

Adapun tujuan pada penelitian ini adalah : "Untuk mengetahui Strategi Bisnis yang dapat dilakukan dalam meningkatkan penjualan pada Kemplang Panggang Fajar

\section{Tinjauan Pustaka}

\section{Pengertian Manajemen Strategi}

Menurut Hubies dan Najib (2014).

Manajemen strategi adalah seperangkatkeputusan dan tindakan manajerialyang menentukan kinerja organisasi dalamjangaka panjang".

\section{Definisi Manajemen}

MenurutAbdulah(2014)Manajemenituadal ahkeseluruhan aktivittas yang berkenaan dengan melaksanakan perkerjaan organisasi melalui fungsi-fungsi perencanaan, pengorganisasian, pengarahan, dan pengawasan untuk mencapai tujuan organisasi yang sudah di tetapkan dengan bantuan sumber daya organisasi(man,money,material,mechine,a ndmethod) secara efesien dan efektif.

\section{Manfaat Manajemen Strategi}

Menurut David(2011), Secara historis manfaat utama dari manajemen strategis adalah untuk membantu organisasi merumuskan strategi-strategi yang lebih baik melalui penggunaan pendekatan terhadap pilihan strategi yang lebih sistematis, logis, danrasional. Manfaat lainnya adalah dapat membantuorganisasi beradaptasi pada perubahan-perubahan yang terjadi. Keuntungan yang diperoleh dari penerapan manajemen strategi ada dua yaitukeuntungankeuangandankeuntungan nonkeuangan.

\section{Gambar 2.1}

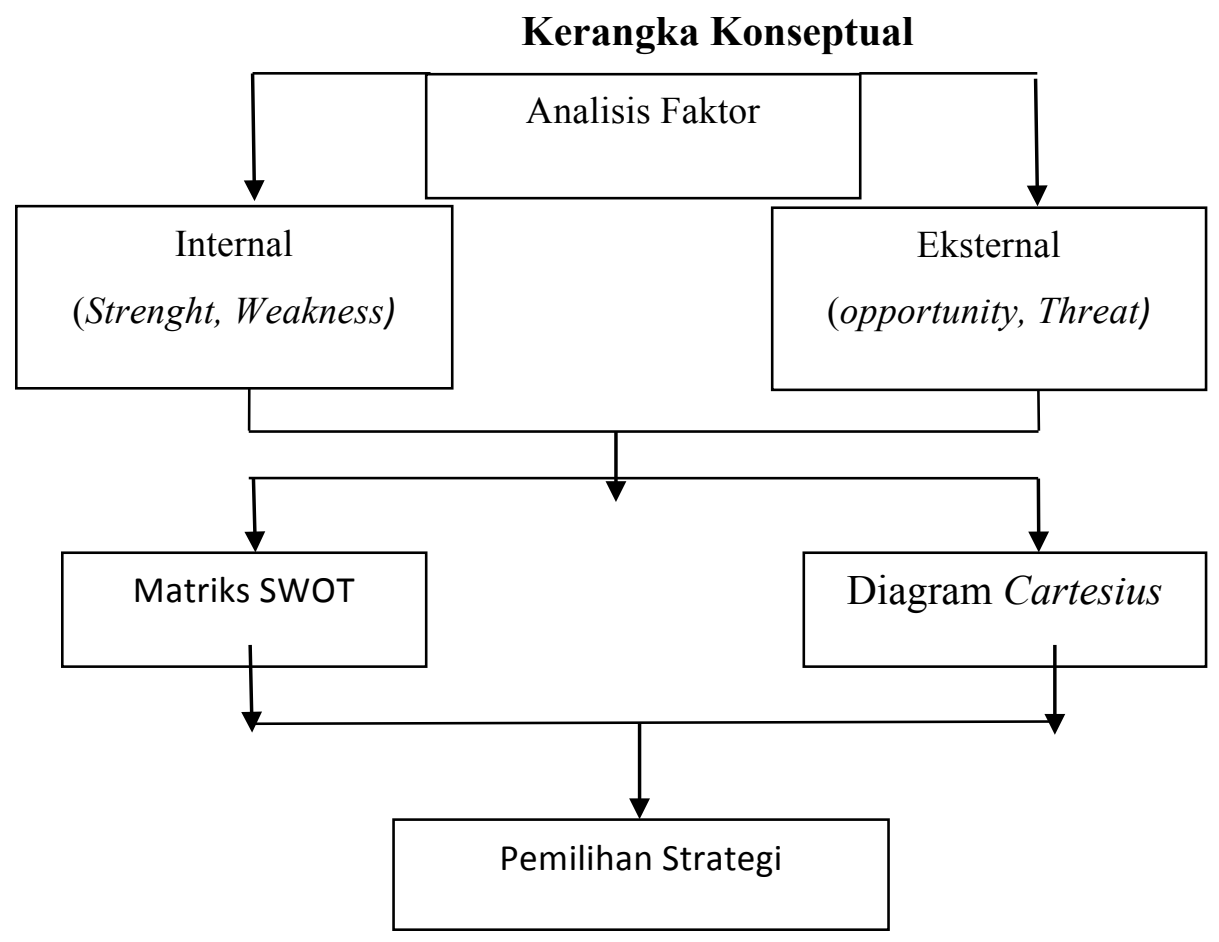




\section{METODE PENELITIAN}

\section{Jenis Penelitian}

1. Penelitian Pustaka (libraryResearch)

Penelitian kepustakaan dilakukan dengan cara mempelajari literatur-literatur yang berkaitan dengan penelitian mengenai analisis strategi.

2. Peneliti lapangan (Field Research)

Penelitian ini mengadakan tinjauan langsung kepada pemilik Usaha Kemplang Panggang Fajar Bandar Lampung.

\section{Desain Penelitian}

Desain penelitian yang digunakan adalah desain penelitiandeskriptif yaitu prosedur atau cara pemecahan masalah dengan cara menggambarkan ataumelukiskan suatu fenomena, keadaan atau peristiwa pada masa sekarang. Tujuan dari penelitian deskriptif ini adalah untukmembuat deskripsi atau gambaransecara sistematis, faktual dan akurat mengenai fakta-fakta, sifat-sifat, serta hubungan antara fenomena yang di teliti.

\section{Metode Analisis}

Metode analisis yang digunakan peneliti dalam penelitian ini adalah metode analisis kualitatif, ialah motode yang digunakan untuk menganalisis data dengan menggunakan penalaran dan penelaahan dengan berpedoman pada pendekatan teoritis. Kalaupun ada data berupa angkaangka sifat analisis hanya terbatas pada pemberian informasi, menilai suatu, mengevaluasi data angka tersebut kemudian melakukan penafsiran dan menyimpulkan. Adapun alat analisis yang digunakan dalam penelitian ini ialah Analisis SWOT (Strenghts, Weakness, opportunity And Threats).

\section{HASII PENELITIAN}

\section{Analisis Faktor Internal dan Eksternal Menggunakan IFAS dan EFAS}

Tahap-tahap dalam menyusun tabel internal factor analysis summary (IFAS) dan eksternal factor analysis summary (EFAS) ialah denganmenentukan faktor internal yangmenjadi kekuatandan kelemahan dan faktor eksternal yangmenjadi peluang dan ancaman Kemplang Panggang Fajar Bandar Lampung. Setelah faktor internal dan eksternal Kemplang Panggang Fajar Bandar Lampung diketahui, baru dapat disusun tabel internal factor analysis summary 
(IFAS) dan tabel eksternal factor analysis summary (EFAS). Dalam tabel IFAS dan EFAS, masing-masing faktor di beri bobot dengan skala mulai dari 0,0 (tidakpenting) sampai dengan 1,0 (sangatpenting) dimana semua bobot tersebut jumlahnya tidak melebihi skor total 1,00, faktor-faktor tersebut kemungkinandapatmemberikan dampakterhadap Kemplang Panggang Fajar Bandar Lampung. Setelah masing-masing faktor diberi bobot, tahap selanjutnya adalah menghitung rating untuk masing-masing faktor dengan memberikan skala mulai dari 1(dibawah rata-rata) sampai dengan 4(sangat baik). Nilai rating strength dan weakness selalu bertolak belakang, begitujugadengan opportunity dan threat. Setelah melakukan pembobotan dan ratingmasing-masing faktor, tahapselanjutnya adalah mengalikan bobot masing-masing faktor untuk memperoleh nilai skor. Adapun tabel IFAS dan EFAS Mamikeki Bandar Lampung dapat dilihat pada tabel 4.5 dan 4.6 dibawah ini:

Tabel 4.3 Internal Factor Analysis Summary (IFAS)

\begin{tabular}{|c|l|c|c|c|}
\hline No & \multicolumn{1}{|c|}{ Faktor-faktor Internal } & Bobot & Rating & Bobot x Rating \\
\hline \multicolumn{5}{|c|}{ Kekuatan } \\
\hline 1 & Kualitas Produk Baik & 0.20 & 3 & 0.60 \\
\hline 2 & Stok produk selalu ada & 0.20 & 3 & 0.40 \\
\hline 3 & $\begin{array}{l}\text { Perusahaan memberikan } \\
\text { potongan harga penjualan }\end{array}$ & 0.10 & 2 & 0.20 \\
\hline 4 & Sambal tanpa pengawet & 0.15 & 3 & 0.45 \\
\hline & \multicolumn{5}{|c|}{ Sub Total } & $\mathbf{0 . 6 5}$ & 1.85 \\
\hline & Kelemahan & \\
\hline 1 & Kurangnya promosi & 0.10 & 2 & 0.20 \\
\hline
\end{tabular}




\begin{tabular}{|c|l|c|c|c|}
\hline 2 & Kurangnya tenaga pemasaran & 0.15 & 2 & 0.30 \\
\hline 3 & Sambal tidak tahan lama & 0.05 & 3 & 0.15 \\
\hline 4 & Lokasi yang tidak strategis & 0.05 & 3 & 0.15 \\
\hline & Sub Total & & & \\
\hline \multicolumn{2}{|c|}{ Total } & $\mathbf{0 . 3 5}$ & & $\mathbf{0 . 8 0}$ \\
\hline & $\mathbf{1 . 0 0}$ & & $\mathbf{2 . 6 5}$ \\
\hline
\end{tabular}

Sumber : Data diolah, 2020.

Berdasarkan perhitungan pada tabel 4.3 internal factor analysis summary (IFAS) diatas, diketahui faktor strength mempunyai total nilai skor 1,85 sedangkan weakness mempunyai total nilai skor 1,30. Adapun total nilai skor keseluruhan faktor internal adalah 2,65.

Adapun faktor-faktor strategi eksternal juga dilakukan identifikasi yang hasilnya ada pada tabel 4.4 eksternal factor analysis summary (EFAS) berikut ini:

Tabel 4.6 Eksternal Factor Analysis Summary (EFAS)

\begin{tabular}{|c|c|c|c|c|}
\hline No & Faktor-faktor Eksternal & Bobot & Rating & Bobot x Rating \\
\hline \multicolumn{5}{|c|}{ Peluang } \\
\hline 1 & $\begin{array}{l}\text { Memiliki banyak konsumen yang } \\
\text { setia }\end{array}$ & 0.15 & 3 & 0.45 \\
\hline 2 & $\begin{array}{l}\text { Konsumen sering membeli produk } \\
\text { dalam jumlah banyak }\end{array}$ & 0.15 & 2 & 0.30 \\
\hline 3 & $\begin{array}{l}\text { Memiliki hubungan yang baik } \\
\text { dengan konsumen }\end{array}$ & 0.15 & 4 & 0.60 \\
\hline 4 & $\begin{array}{l}\text { Banyak konsumen yang menyukai } \\
\text { kemplang }\end{array}$ & 0.15 & 4 & 0.60 \\
\hline & Sub Total & 0.60 & & 1.95 \\
\hline \multicolumn{5}{|c|}{ Ancaman } \\
\hline 1 & Memiliki banyak pesaing & 0.15 & 2 & 0.30 \\
\hline 2 & Adanya kesamaan produk & 0.10 & 2 & 0.20 \\
\hline 3 & Pesaing gencar melakukan promosi & 0.10 & 2 & 0.20 \\
\hline 4 & Lokasi pesaing yang lebih strategis & 0.05 & 3 & 0.15 \\
\hline & Sub Total & 0.40 & & 0.85 \\
\hline
\end{tabular}




\begin{tabular}{|c|c|c|c|}
\hline Total & 1.00 & & $\mathbf{2 . 8 0}$ \\
\hline
\end{tabular}

Sumber : Data diolah, 2020.

Berdasarkan perhitungan pada tabel 4.6 eksternal factor analysis summary (EFAS) diatas, diketahui faktor Peluang mempunyai nilai skor 1,95 dan Ancaman mempunyai total nilai 1,40 dan total nilai keseluruhan faktor eksternal adalah 2,80.

Selanjutnya nilai skor masing-masing faktor dapat dirinci, Kekuatan : 1,85, Kelemahan: 0,80, Peluang : 1,95 dan Ancaman : $\mathbf{0 , 8 5}$. Sedangkan total nilai skor keseluruhan untuk faktor internal adalah : $\mathbf{2 , 6 5}$ dan faktor eksternal adalah $\mathbf{2 , 8 0}$.

\section{Diagram Matrix SWOT}

Diagram Matrix SWOT adalah tahap analisis selanjutnya setelah tabel IFASdanEFAS dibuat.Berdasarkan tabel IFAS dan EFAS diketahui nilai Kekuatan dengan Kelemahan mempunyai selisih 1,05 dan nilai Peluang dengan Ancaman mempunyai selisih 1,10. Dari hasil identifikasi faktor-faktor tersebut dapat digambarkan dalam diagram matrik SWOT yang dapat dilihat pada gambar 4.1 dibawah ini:

\section{Gambar 4.1 Diagram Matrix SWOT KEMPLANG PANGGANG FAJAR Bandar Lampung}

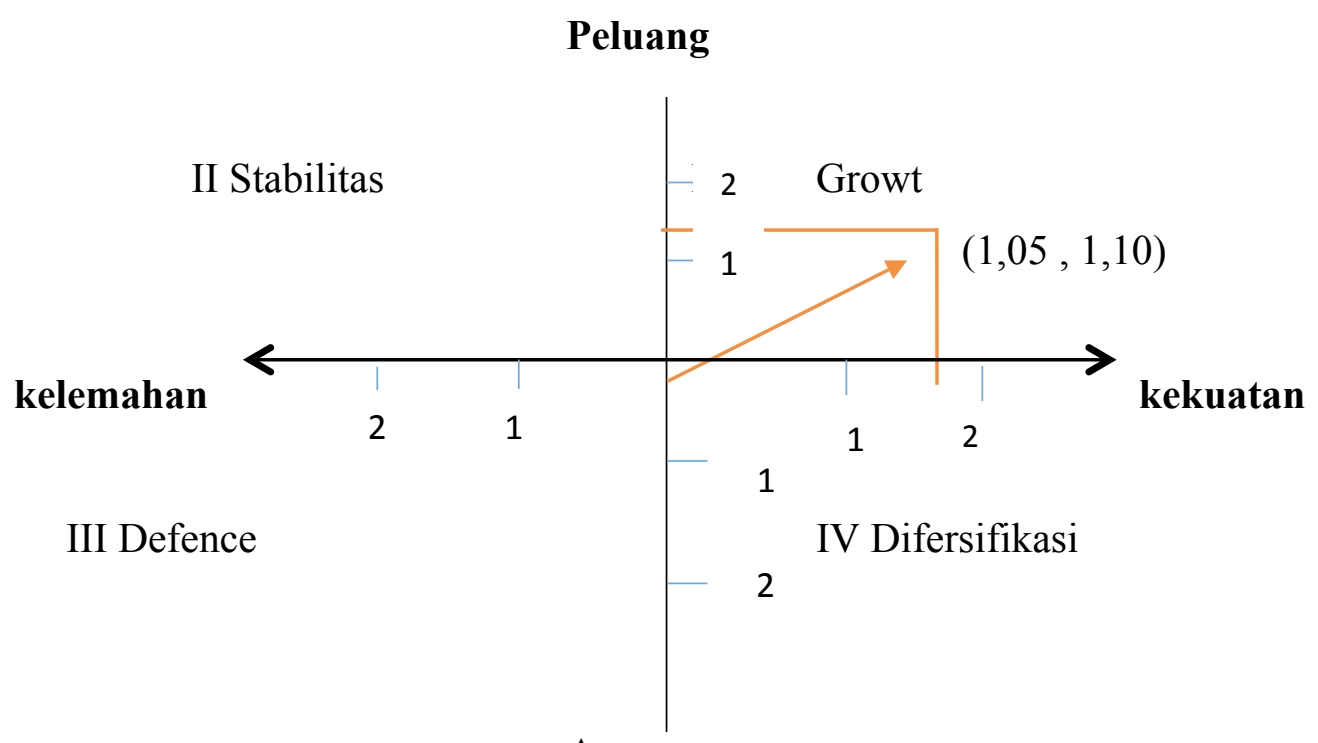

Ancaman

Sumber : data diolah tahun 2020 
Berdasarkan diagram Matrix SWOT diatas, diketahui Kemplang Panggang Fajar Bandar Lampung berada di kaudran I, dimana situasi yangsangat menguntungkan. Padakuadranini, Kemplang Panggang Fajar Bandar Lampung memiliki peluang dan kekuatansehinggadapat memanfaatkan peluang yang ada.Strategi yang harus diterapkan dalamkondisi ini adalah mendukung kebijakan pertumbuhan yang agresif (growth orientedstrategy).

\section{Matrix SWOT}

Pada tabel 4.3 dan tabel 4.6 didapatkan hasil analisis matriks IFAS dan EFAS yang telah disusun pada matriks SWOT untuk menganalisis rumusan alternatif strategi strengthopportunity (SO), weakness-opportunity (WO), strength-threat(ST)danweakness-threat (WT). Hasil analisis matriks SWOTdapat dilihat pada tabel 4.8 dibawah ini:

Tabel 4.7 Kombinasi Strategi Matrik SWOT

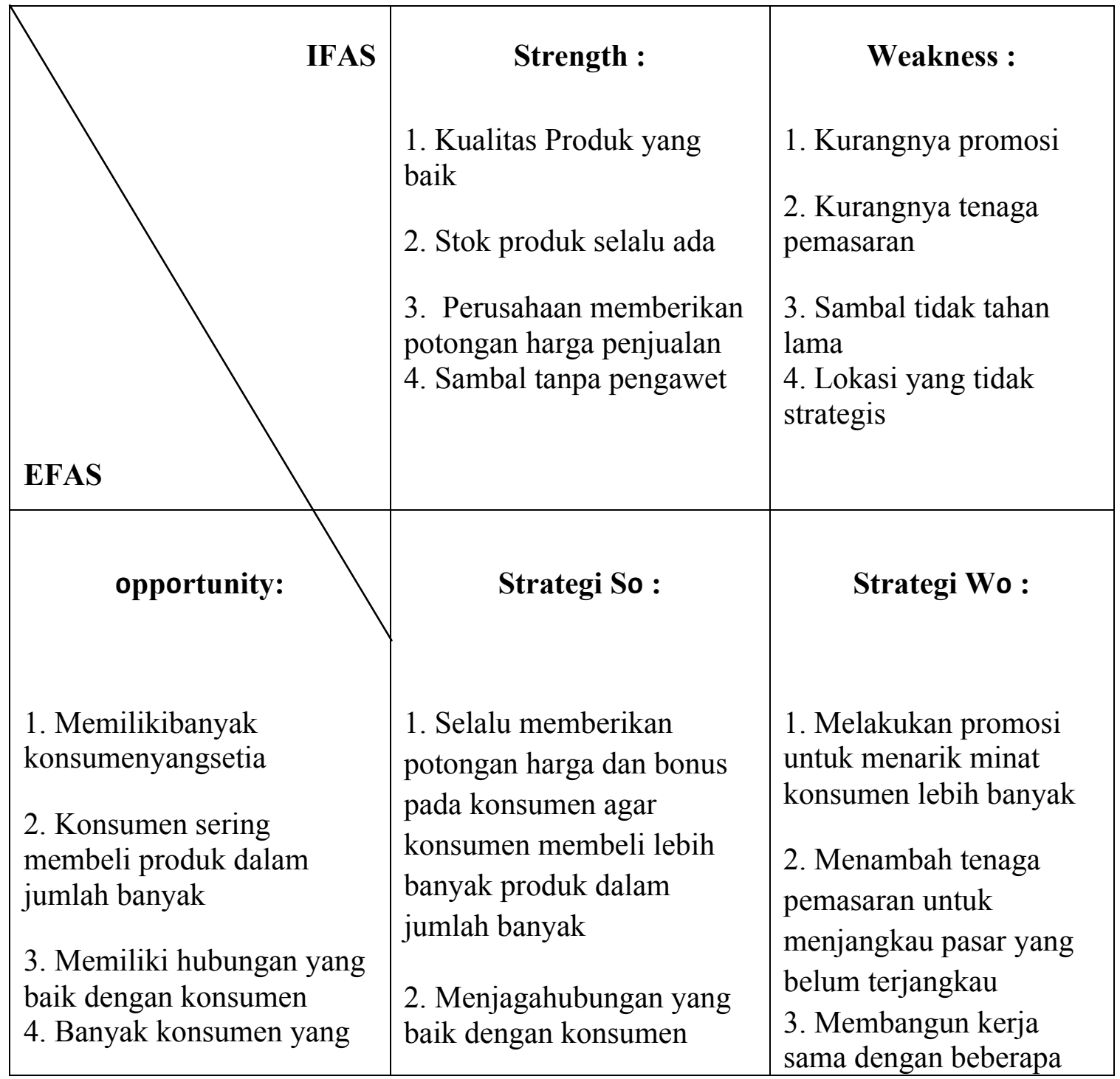




\begin{tabular}{|c|c|c|}
\hline menyukai kemplang & $\begin{array}{l}\text { dengan cara menjaga } \\
\text { kualitas dan stock produk } \\
\text { 3. Meningkatkan sosialisasi } \\
\text { keunggulan Produk melalui } \\
\text { media promosi }\end{array}$ & $\begin{array}{l}\text { influencer agar } \\
\text { mempromosikan dan } \\
\text { dapat meningkatkan } \\
\text { penjualan }\end{array}$ \\
\hline Threath : & StrategiST : & StrategiWT : \\
\hline $\begin{array}{l}\text { 1. Memiliki banyak pesaing } \\
\text { 2. Adanya kesamaan produk } \\
\text { 3. Pesaing gencar } \\
\text { melakukan promosi } \\
\text { 4. Lokasi pesaing yang } \\
\text { lebih strategis }\end{array}$ & $\begin{array}{l}\text { 1. Meningkatkan kualitas } \\
\text { dan mutuproduk } \\
\text { 2. Melakukan riset pasar } \\
\text { untuk mengetahui harga } \\
\text { pesaing } \\
\text { 3. Menjaga ketersediaan } \\
\text { stok atau bahkan menambah } \\
\text { ketersediaan stok kemplang } \\
\text { agar konsumen tidak } \\
\text { menunggu lama }\end{array}$ & $\begin{array}{l}\text { 1. Meningkatkan } \\
\text { kegiatan-kegiatan } \\
\text { promosi melalui } \\
\text { tenaga pemasaran } \\
\text { 2. Membuka tempat } \\
\text { baru yang mudah } \\
\text { dijangkau } \\
\text { konsumen }\end{array}$ \\
\hline
\end{tabular}

Sumber: peneliti tahun 2020

\section{KESIMPUIAN DAN SARAN \\ Kesimpulan}

Berdasarkan uraian dan pembahasan yang telah di kemukakan pada bab-bab sebelumnya maka dapat ditarik beberapa pokok-pokok yang menjadi kesimpulan dalam penulisan ini ialah, dari analisis SWOT dapat disimpulkan beberapa strategi yang dapat diterapkan oleh Kemplang Panggang Fajar Bandar Lampung dalam upaya untuk meningkatkan penjualan, adalah :

\section{Strategi SO}

- Selalu memberikan potongan harga dan bonus pada konsumen agar konsumen membeli lebih banyak produk dalam jumlah banyak

- Menjaga hubungan yang baik dengan konsumen dengan cara menjaga kualitas dan stock produk

- Meningkatkan sosialisasi keunggulan Produk melalui media promosi 
2. Strategi WO

- Melakukan promosi untuk menarik minat konsumen lebih banyak

- Menambah tenaga pemasaran untuk menjangkau pangsa pasar yang belum terjangkau

- Membangun kerja sama dengan beberapa influencer agar mempromosikan kemplang yang akan dapat meningkatkan penjualan

\section{Strategi ST}

- Meningkatkan kualitas dan mutu produk

- Melakukan riset pasar untuk mengetahui harga pesaing

- Menjaga ketersediaan stok atau bahkanmenambah ketersediaan stok kemplang agar konsumen tidak menunggu lama
- Meningkatkan kegiatankegiatan promosi melalui tenaga pemasaran

- Membuka tempat baru yang mudah dijangkau konsumen

\section{Saran}

Dari hasil uraian dan pembahasan yang telah di kemukakan maka terdapat beberapa pokok saran yang dapat dipertimbangkan Kemplang Panggang Fajar Bandar Lampung adalah sebagai berikut :

1. Dalam melakukan startegi bisnis hendaknya perlu membuat strateg bisnis yang lebih baik dengan memperhatikan startegi yang telah dijalankan sebelumnya. Tetapi yang perlu diperhatikan adalah strategi penetapan harga dan potongan penjualan yang diberikan.

2. Dari kesimpulan analisis SWOT hal-hal yang dapat dilakukan oleh pihak Kemplang Panggang Fajar Bandar Lampung dalam upaya meningkatkan volume

4. Strategi WT 
penjualan kemplang antara lain

adalah dengan pemberian

potongan harga dan bonus,

menjaga hubungan baik dengan

konsumen dan melakukan

kegiatan-kegiatan promosi

secararutin, meningkatkan

kualitas dan mutu produk, serta menjaga ketersediaan stok atau

bahkan menambah ketersediaan stok produk. Perusahaan juga harus menambah tenaga pemasaran agar kemplang dapat terjual secara maksimal.

\section{DAFTAR PUSTAKA}

Assauri. (2011).Strategic Management Sustainable competitive advantage. Indonesia, Jakarta.

Bilung, (2016).Analisis SWOT dalam Menentukan Strategi Pemasaran Sepeda Motor Honda pada CV. Semoga Jaya di Area Muara Wahau Kabupaten Kutai Timur. Universitas Mulawarman : ejournal Administrasi Bisnis.

Jayanti, Dewi (2011). Analisis swot sebagai strategi meningkatkan daya saing pada hotel cherry pink Kh.Wahid Hasyim

Lukmandono.(2015).Analisis SWOT untuk Menentukan Keunggulan Strategi Bersaing di Sektor Industri Manufaktur. Surakarta : Seminar Nasional Teknik Industri (IDEC III) Program Studi Teknik Industri. Universitas Negeri Sebelas Maret. M.Oktaviannur, AppinPuriskyRedaputri (2020). Analysis of business strategy decision making in increasing sales of waroeng steak and shake Bandar Lampung

M Yusuf S Barusman, Appin Purisky Redaputri(2021). Analisis strategi bisnis Marley's Café COfee and Resto Bandar Lampung
Meleong. (2011). MetodologiPenelitian Kualitatif Edisi Revisi. Bandung: PT.Remaja Rosdakarya

NisakZuhrotun (2013).Analisis swot untuk menentukan strategi kompetitif

Purwanto. (2013). Komunikasi Bisnis. Erlangga.

Rangkuti,F. (2014).Teknik Membedah KasusBisnisAnalisis SWOT.Jakarta: GramediaPustakaUtama. Rangkuti,F.(2016).

TeknikMembedahKasusBisnisAnalisis SWOT.Jakarta: GramediaPustakaUtama. Sari, Fitria Komala (2017). Strategi Pengembangan Usaha Bakso Sony di Bandar Lampung

Turnip Ignacencia Catherine S (2018). Analisis strategi swot untuk menghasilkan competitive advantages pada usaha kecil dan menengah di Bandar Lampung (studi kasus pada kantin Universitas Bandar Lampung)

Wijaya, Olivia (2015). AnalisisStrategi pemasarandalammeningkatkanvolume penjualanpada PT. Sangga Buana Seputih Banyak Lampung Tengah 